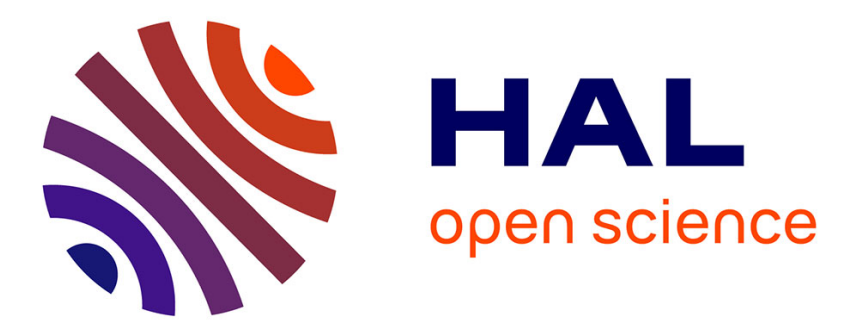

\title{
Finite elements simulations of thin copper sheets blanking: study of blanking paramaters on sheared edge quality
}

C. Husson, J.P.M. Correia, Loïc Daridon, Saïd Ahzi

\section{- To cite this version: \\ C. Husson, J.P.M. Correia, Loïc Daridon, Saïd Ahzi. Finite elements simulations of thin copper sheets blanking: study of blanking paramaters on sheared edge quality. Journal of Materials Processing Technology, 2008, 199 (1-3), pp.74-83. 10.1016/j.jmatprotec.2007.08.034 . hal-00447196}

\author{
HAL Id: hal-00447196 \\ https://hal.science/hal-00447196
}

Submitted on 22 Sep 2016

HAL is a multi-disciplinary open access archive for the deposit and dissemination of scientific research documents, whether they are published or not. The documents may come from teaching and research institutions in France or abroad, or from public or private research centers.
L'archive ouverte pluridisciplinaire HAL, est destinée au dépôt et à la diffusion de documents scientifiques de niveau recherche, publiés ou non, émanant des établissements d'enseignement et de recherche français ou étrangers, des laboratoires publics ou privés. 


\title{
Finite elements simulations of thin copper sheets blanking: Study of blanking parameters on sheared edge quality
}

\author{
C. Husson ${ }^{1}$, J.P.M. Correia*, L. Daridon ${ }^{2}$, S. Ahzi \\ IMFS, UMR 7507, Université Louis Pasteur, 2 rue Boussingault, 67000 Strasbourg, France
}

\begin{abstract}
The capabilities of finite elements codes allow now accurate simulations of blanking pro-cesses when appropriate materials modelling are used. Over the last decade, numerous numerical studies have focused on the influence of process parameters such as punch-die clearance, tools geometry and friction on blanking force and blank profile (sheared edge). The proposed study focuses on the finite elements simulations of a blanking process using a new viscoplastic model for the evolution of the flow stress coupled with a new damage model. The commercial finite elements code ABAQUS/Explicit has been chosen to simulate the blanking process. The finite elements predictions have been compared with experimen-tal results. Then the finite elements simulations have been used to assess the influence of punch-die clearance as well as the influence of tool wear and friction on sheared edge quality.
\end{abstract}

Keywords:

Blanking; Finite elements ; Sheared edge ; Damage ; Viscoplasticity

\section{Introduction}

A blanking operation consists in cutting a sheet by subjecting it to shear stresses. The shearing process develops between a punch and a die and leads to the total rupture of the sheet. Blanking process is widely used in the manufacturing of small components such as electronic and electrical connectors for automotive or telecommunication industries. In these high productivity industries the components are obtained using high stroke rates. Punch and die geometry (i.e. punch and die corner radii), punch rate, lubrication, the clearance between the punch and the die (also called blanking clearance) and the properties of the metal sheet influence the shearing process (Kalpakjian, 1997).

Classically, the choice of the process parameters for sheet metal forming was determined empirically by an iterative procedure involving a large number of expensive tests. Analytical analyses (Klingenberg and Singh, 2005) have also been developed for process control and tool design. In the last few years, with the increase of computational capabilities, numerous finite elements analyses (Taupin et al., 1996; Brokken et al., 1998; Hambli and Potiron, 2000) have led to a better understanding of the mechanics involved in the blanking process. Various ductile fracture criteria (McClintock, 1968; Cockroft and Latham, 1968; Gurson, 1977; Lemaitre, 1985) have been proposed to predict the crack initiation. They have been implemented in different finite elements codes to simulate sheet metal blanking. Different strategies, such as the element deletion method and the finite elements separation method (Lemiale, 2004), have also been proposed to simulate the crack propagation in blanking. Consequently finite elements (FE) analysis can now be used to improve process and tool design.

\footnotetext{
* Corresponding author. Tel.: +33 3902429 54; fax: +33 388614300 .

E-mail address: pedro@imfs.u-strasbg.fr (J.P.M. Correia).

${ }^{1}$ Present address: Techlam, Hutchinson Group, 1 rue de l'Industrie, BP 60146, 67801 Cernay Cedex, France.

2 Present address: LMGC, UMR 5508, Université Montpellier II, CC 048 Place Eugène Bataillon, 34095 Montpellier Cedex 5, France.
} 


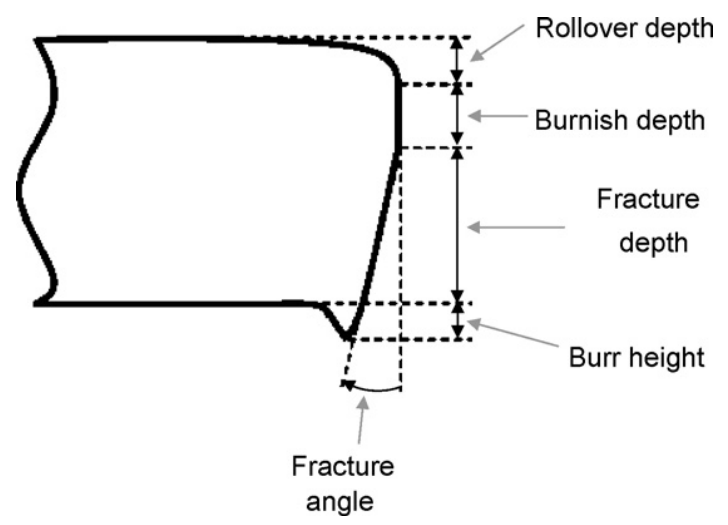

Fig. 1 - Characteristic features of a sheared edge.

The objective of the proposed study is to analyse, in the case of a blanking process for thin copper sheets, the influence of process parameters on the characteristic features of the sheared edge (Fig. 1). A numerical analysis based on the FE method has been carried out. The commercial FE code ABAQUS/Explicit has been used. The viscoplastic hardening law and the damage model proposed by Husson (Husson, 2004) have been implemented in the FE code ABAQUS/Explicit via a user material subroutine VUMAT. In order to investigate the influence of process parameters (blanking clearance, tool wear and friction) on the characteristic features of the sheared edge, the proposed material modelling and the element deletion method have been applied to simulate the plasticity in the sheared zone as well as the fracture initiation and the fracture propagation. We note that our proposed material modelling for plasticity and damage accounts for strain rate and adiabatic heating effect.

\section{Constitutive equations}

\subsection{Viscoplastic hardening model}

This study was conducted using a commercial copper alloy. It was considered that the material had isotropic elastic viscoplastic behaviour. The von Mises yield criterion and the hardening law proposed by Husson (Husson, 2004) have been used. This hardening law is based on the mechanical threshold stress model (i.e. MTS model) proposed by Follansbee and Kocks (Follansbee and Kocks, 1988). The MTS model is based on the theory of dislocations motion which allows a physically based description of the material behaviour through a wide range of temperatures and strain rates. Following the formalism proposed by Follansbee and Kocks (Follansbee and Kocks, 1988) the flow stress $\sigma$ can be split into two parts:

$\sigma=\sigma_{\text {ath }}+\sigma_{\text {th }}$

where $\sigma_{\text {ath }}$ is the athermal component and $\sigma_{\text {th }}$ is the thermal component. The athermal stress $\sigma_{\text {ath }}$ depends on strengthening mechanisms and on grain size. The thermal stress $\sigma_{\text {th }}$ depends on the strain rate $\dot{\varepsilon}$, temperature $\mathrm{T}$ and material microstructure. Following the work of Follansbee and Kocks (Follansbee and Kocks, 1988), the thermal stress $\sigma_{\text {th }}$ is decom- posed as the product of the mechanical threshold stress $\hat{\sigma}_{\text {th }}$ and a function depending on the strain rate and temperature:

$\sigma_{\text {th }}=\hat{\sigma}_{\text {th }}\left[1-\left(\frac{k_{\mathrm{B}} \mathrm{T}}{G_{0}} \ln \left(\frac{\dot{\varepsilon}_{0}}{\dot{\varepsilon}}\right)\right)^{1 / \mathrm{A}}\right]^{1 / \mathrm{B}}$

where $k_{\mathrm{B}}$ is the Boltzmann constant, $G_{0}=\mu b^{3} g_{0}$ the free activation energy (where $b$ is the magnitude of the Burgers vector, $g_{0}$ a normalized activation energy and $\mu$ is the shear modulus), $\dot{\varepsilon}_{0}$ a reference strain rate and $A$ and $B$ are material constants. We assume that the mechanical threshold stress $\hat{\sigma}_{\text {th }}$ could be written as

$\hat{\sigma}_{\text {th }}=\left(\sigma_{\mathrm{qs}}-\sigma_{\text {ath }}\right) R(\dot{\varepsilon}, T)$

where $\sigma_{\mathrm{qs}}$ is the quasi-static flow stress and $\mathrm{R}(\dot{\varepsilon}, \mathrm{T})$ a function describing hardening at high strain rates of the material. Based on the works of Maudlin et al. (Maudlin et al., 1990) and of Johnson and Cook (Johnson and Cook, 1983), we propose to write the function $R(\dot{\varepsilon}, T)$ as follows

$R(\dot{\varepsilon}, T)=\frac{a_{0}+a_{1} \ln (\dot{\varepsilon})+a_{2} \sqrt{\dot{\varepsilon}}}{a_{0}}\left(1-\left(\frac{T-T_{\text {ref }}}{T_{\text {melt }}-T_{\text {ref }}}\right)^{m}\right)$

where $T_{\text {ref }}$ is the reference temperature (in our case room temperature), $T_{\text {melt }}$ the material melting temperature and $m, a_{0}$, $a_{1}$ and $a_{2}$ are material parameters. We derive the expression of the quasi-static flow stress $\sigma_{\mathrm{qs}}$ from the works of Flinn et al (Flinn et al., 2001) and of Kovàcs and Vörös (Kovàcs and Vörös, 1996):

$\sigma_{\mathrm{qs}}=\sigma_{\mathrm{ath}}+\sigma_{\mathrm{m}}\left(1-\ln \left(\frac{\varepsilon}{\varepsilon_{\mathrm{m}}}\right)\right) \varepsilon$

where $\sigma_{\mathrm{m}}$ and $\varepsilon_{\mathrm{m}}$ are material parameters. The material parameter $\sigma_{\mathrm{m}}$ corresponds to a maximum flow stress and the material parameter $\varepsilon_{\mathrm{m}}$ corresponds to a maximum plastic strain. The final expression of the proposed flow stress is therefore given by

$$
\begin{aligned}
\sigma= & \sigma_{\text {ath }}+\sigma_{\mathrm{m}}\left(1-\ln \left(\frac{\varepsilon}{\varepsilon_{\mathrm{m}}}\right)\right) \varepsilon \frac{a_{0}+a_{1} \ln (\dot{\varepsilon})+a_{2} \sqrt{\dot{\varepsilon}}}{a_{0}} \\
& \times\left(1-\left(\frac{\mathrm{T}-\mathrm{T}_{\text {ref }}}{\mathrm{T}_{\text {melt }}-\mathrm{T}_{\text {ref }}}\right)^{m}\right)\left[1-\left(\frac{k_{\mathrm{B}} \mathrm{T}}{G_{0}} \ln \left(\frac{\dot{\varepsilon}_{0}}{\dot{\varepsilon}}\right)\right)^{1 / \mathrm{A}}\right]^{1 / \mathrm{B}}
\end{aligned}
$$

An example of hardening curves obtained with relation (6) has been plotted in Fig. 2. The hardening law (6) is in agreement with the experimental results (Follansbee and Kocks, 1988; Tanner et al., 1999) obtained for oxygen-freehigh-conductivity coppers (i.e. OFHC coppers). Based on comparisons with experimental results (Husson, 2004), it can be concluded that the hardening law (6) is suitable for copper alloys, and for strain rates up to $10^{4} \mathrm{~s}^{-1}$ and for a temperature range restricted to $76 \mathrm{~K} \leq \mathrm{T} \leq \mathrm{T}_{\text {melt }} / 2$.

\subsection{Damage model}

The damage model used in this study is briefly reviewed below. It is based on isotropic continuum damage mechanics (i.e. $\mathrm{CDM}$ ) where a damage parameter $\mathrm{D}$ is introduced. This is a 

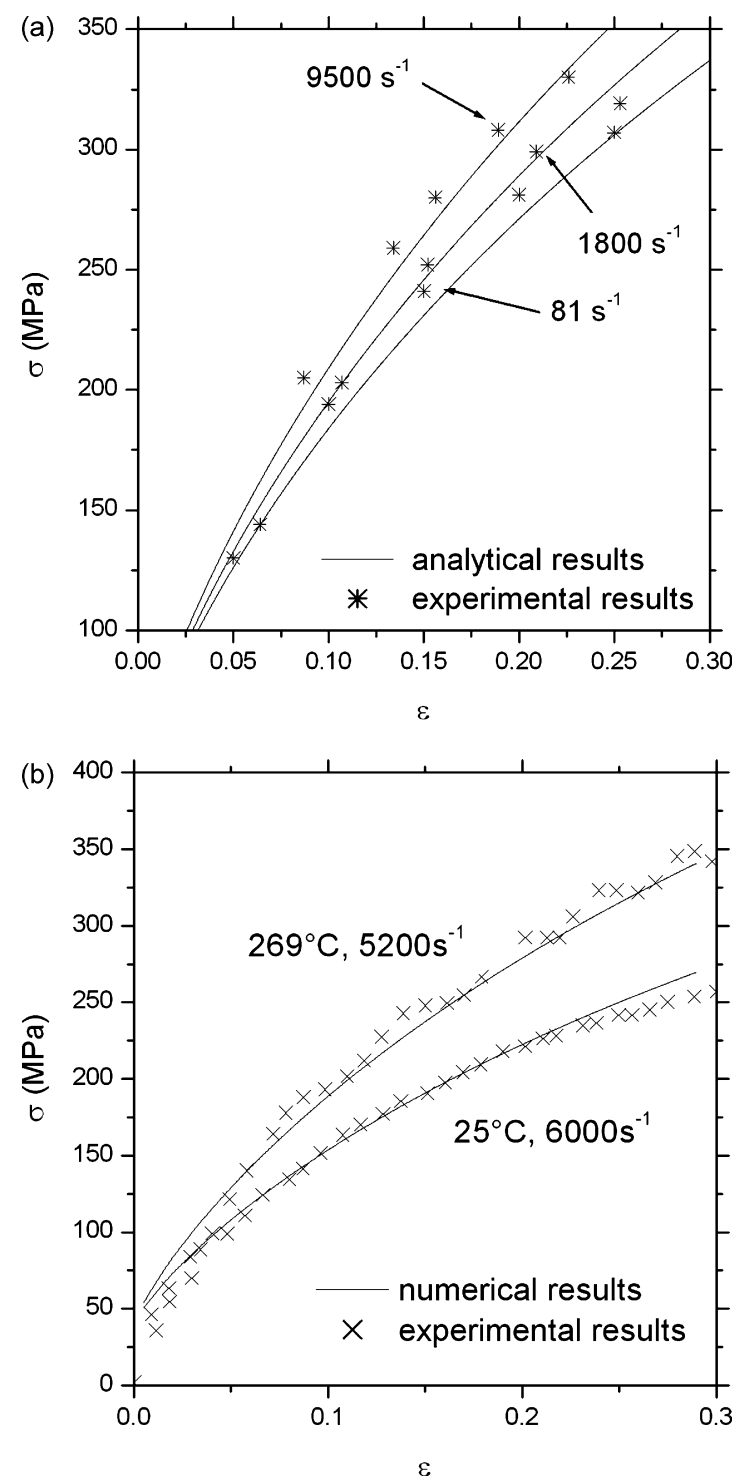

Fig. 2 - Comparison between the hardening curves predicted by our model and the experimental results (case (a) for different strain rates (Johnson and Cook, 1983) and case (b) for different temperatures (Tanner et al., 1999)).

fully coupled plasticity/damage model. The proposed damage law (the details can be found in the work of Husson and coworkers (Husson, 2004; Husson et al., in press)) can be written as

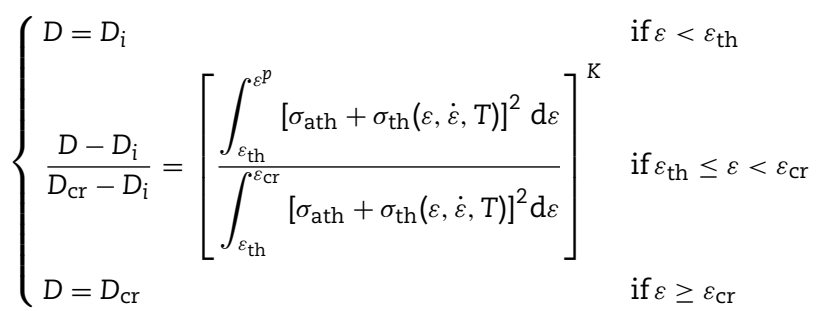

where $\varepsilon_{\text {th }}$ is the threshold strain at which damage initiates, $\varepsilon_{\text {cr }}$ the strain value at fracture, $D_{i}$ the initial damage value of the material (in our case the initial damage is null) and $D_{\mathrm{cr}}$ is the critical damage value for failure. The expressions of the threshold strain at which damage is initiated $\varepsilon_{\text {th }}$ and of the strain value at fracture $\varepsilon_{\mathrm{cr}}$ are given by

$\varepsilon_{\text {th }}\left(\dot{\varepsilon}, T, \frac{\sigma_{\mathrm{H}}}{\sigma^{\mathrm{e}}}\right)=\varepsilon_{\text {th }}^{\mathrm{u}}(\dot{\varepsilon}, \mathrm{T})\left[\frac{\varepsilon_{\mathrm{cr}}^{\mathrm{qs}}}{\varepsilon_{\text {th }}^{\mathrm{qs}}}\right]^{1 / f\left(\sigma_{\mathrm{H}} / \sigma^{\mathrm{e}}\right)-1}$

$\varepsilon_{\mathrm{Cr}}\left(\dot{\varepsilon}, \mathrm{T}, \frac{\sigma_{\mathrm{H}}}{\sigma^{\mathrm{e}}}\right)=\varepsilon_{\mathrm{th}}^{\mathrm{u}}(\dot{\varepsilon}, \mathrm{T})\left[\frac{\varepsilon_{\mathrm{cr}}^{\mathrm{u}}(\dot{\varepsilon}, \mathrm{T})}{\varepsilon_{\mathrm{th}}^{\mathrm{u}}(\dot{\varepsilon}, \mathrm{T})}\right]^{1 / f\left(\sigma_{\mathrm{H}} / \sigma^{\mathrm{e}}\right)}$

where $\sigma_{\mathrm{H}}$ is the hydrostatic pressure, $\sigma^{\mathrm{e}}$ the von Mises equivalent stress, $\varepsilon_{\text {th }}^{\text {qs }}$ the uni-axial quasi-static threshold strain, $\varepsilon_{\mathrm{cr}}^{\mathrm{qs}}$ the uni-axial quasi-static strain value at fracture, $\varepsilon_{\text {th }}^{\mathrm{u}}(\dot{\varepsilon}, \mathrm{T})$ the uni-axial threshold strain, $\varepsilon_{\mathrm{cr}}^{\mathrm{u}}(\dot{\varepsilon}, \mathrm{T})$ the uni-axial strain value at fracture and $f\left(\sigma_{\mathrm{H}} / \sigma^{\mathrm{e}}\right)$ is the tri-axiality stress factor. The uni-axial quasi-static threshold strain $\varepsilon_{\text {th }}^{\mathrm{qs}}$ and the uni-axial quasi-static strain value at fracture $\varepsilon_{\mathrm{cr}}^{\mathrm{qs}}$ are material parameters. We propose the following expressions for assessing the uni-axial threshold strain and fracture strain

$\varepsilon_{\text {th }}^{\mathrm{u}}(\dot{\varepsilon}, \mathrm{T})=\varepsilon_{\mathrm{th}}^{\mathrm{qs}}\left[b_{1}+b_{2} \ln (\dot{\varepsilon})+b_{3} \sqrt{\dot{\varepsilon}}\right]\left[1+\beta \frac{\mathrm{T}-\mathrm{T}_{\text {ref }}}{\mathrm{T}_{\text {melt }}-\mathrm{T}_{\text {ref }}}\right]$

$\varepsilon_{\mathrm{cr}}^{\mathrm{u}}(\dot{\varepsilon}, \mathrm{T})=\varepsilon_{\mathrm{cr}}^{\mathrm{qs}}\left[b_{1}+b_{2} \ln (\dot{\varepsilon})+b_{3} \sqrt{\dot{\varepsilon}}\right]\left[1+\beta \frac{\mathrm{T}-\mathrm{T}_{\text {ref }}}{\mathrm{T}_{\text {melt }}-\mathrm{T}_{\mathrm{ref}}}\right]$

where $b_{1}, b_{2}, b_{3}$ and $\beta$ are material parameters. The tri-axiality stress factor has been defined as in (Lemaitre, 1985) and can be written as follows:

$f\left(\frac{\sigma_{\mathrm{H}}}{\sigma^{\mathrm{e}}}\right)=\left[\frac{2}{3}(1+v)+3(1-2 v)\left[\frac{\left\langle\sigma_{\mathrm{H}}\right\rangle_{+}}{\sigma^{\mathrm{e}}}\right]^{2}\right]$

where $v$ is the Poisson ratio. The function $\left\langle\sigma_{\mathrm{H}}\right\rangle_{+}$is defined by $\left\langle\sigma_{\mathrm{H}}\right\rangle_{+}=\sigma_{\mathrm{H}}$ when $\sigma_{\mathrm{H}}>0$ and by $\left\langle\sigma_{\mathrm{H}}\right\rangle_{+}=0$ when $\sigma_{\mathrm{H}}<0$. The damage model defined by Eq. (7) is compared with the experimental results obtained by Dufailly (1980) for an OFHC copper. Dufailly (Dufailly, 1980) has carried out quasi-static tensile tests at room temperature. The void evolution has not been measured directly but was estimated by the measured variations of the elastic modulus as a function of strain under loading-unloading conditions. The analytical results of (7) and the experimental results (Dufailly, 1980) have been plotted in Fig. 3 which shows that the analytical predictions are in agreement with the experiments. Because of the absence of experimental data for damage at high strain rates, we simply assume that our model will lead to appropriate results at high strain rates.

To account for damage effects on the evolving deformation response of the material, the flow stress given by Eq. (6) and the Young modulus have been coupled with the damage law (7). The damaged material behaviour is then described by the following equations:

$E=E_{0}(1-D), \quad \sigma=\sigma_{0} \sqrt{1-D}$

where $E_{0}$ is the initial Young modulus and $\sigma_{0}$ is the initial flow stress given by the hardening law (6). The selection of $\sqrt{1-D}$ in 


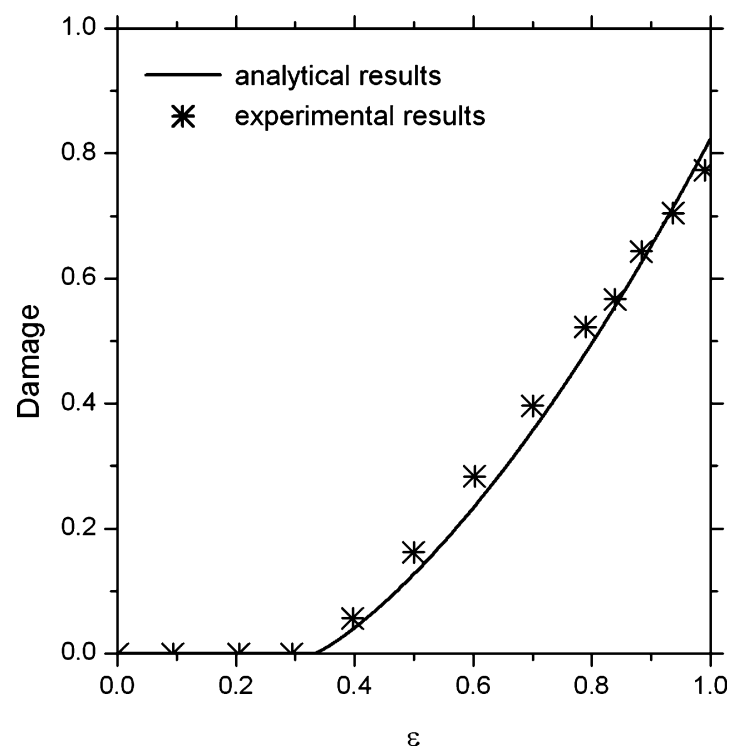

Fig. 3 - Comparison between the damage evolution predicted with Eq. (7) and the experimental results obtained by (Dufailly, 1980) for $\dot{\varepsilon}=0.004 \mathrm{~s}^{-1}$ and $\mathrm{T}=298 \mathrm{~K}$.
Table 1 - Tooling dimensions

Punch diameter $\left(D_{\mathrm{p}}\right)$

$3.5 \mathrm{~mm}$

Die diameter $\left(D_{m}\right)$

Punch corner radius $\left(R_{\mathrm{p}}\right)$

Die corner radius $\left(R_{d}\right)$

$10 \mu \mathrm{m}$

$10 \mu \mathrm{m}$

Punch-holder clearance

Punch-die clearance, $J$

$5 \mu \mathrm{m}$

Cutting frequency

$15 \mu \mathrm{m}$

700 strokes/min

the second equation of (13) is based on the principle of energy conservation (Husson, 2004; Husson et al., in press).

\section{FE model}

The geometry of the blanking process modelled in this study is presented in Fig. 4. The geometry presented in Fig. 4 is characteristic of small components such as electronic and electrical connectors. The dimensions of the tooling are defined in Table 1. The punch rate is defined with the cutting frequency (Table 1). The initial sheet thickness $t_{0}$ is equal to $0.58 \mathrm{~mm}$. The sheet is made of a commercial copper alloy. The material behaviour of the copper alloy is assumed to obey to the J2

(a)

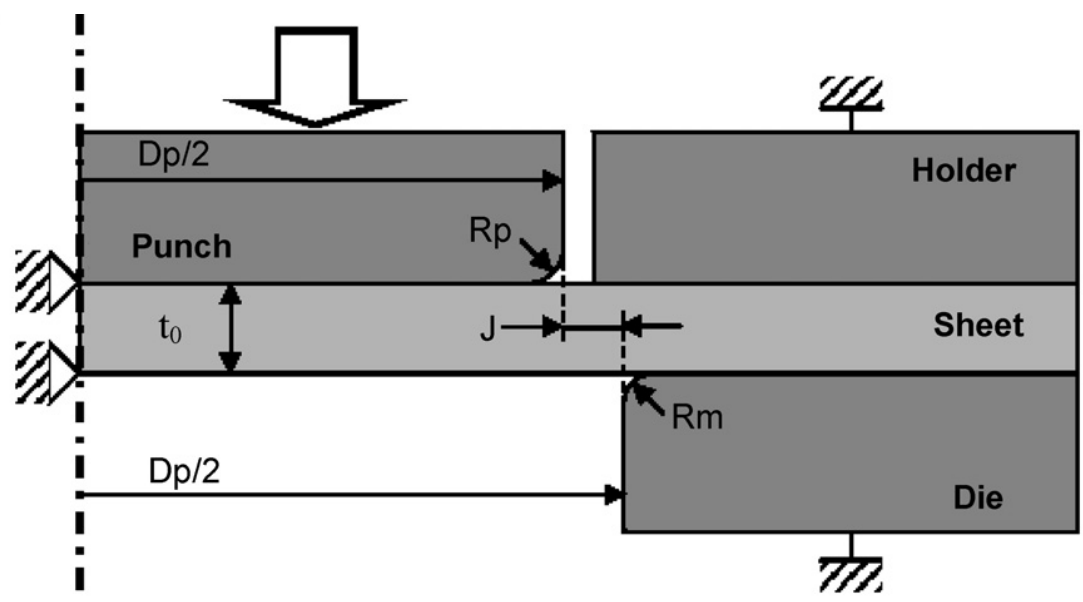

(b)
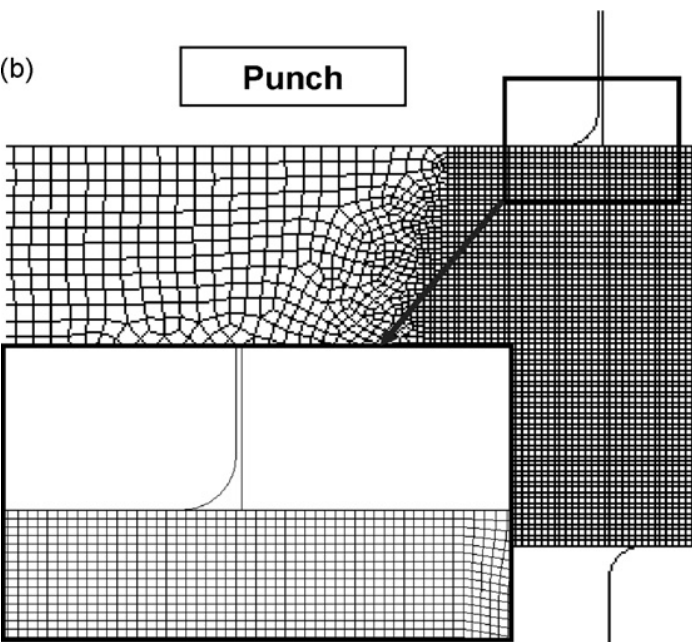

Holder

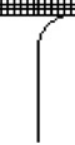

Die

Fig. 4 - Geometry (a) and FE mesh (b) used in the numerical simulations of the blanking process. 


\begin{tabular}{ll} 
Table 2 - Material constants for the commercial copper \\
alloy \\
\hline$E(\mathrm{GPa})$ & 120 \\
$v$ & 0.340 \\
$\sigma_{\text {ath }} / \sigma_{\mathrm{m}}$ & 1.265 \\
$\varepsilon_{\mathrm{m}}^{p}$ & 1.422 \\
$k_{\mathrm{b}} / b^{3}(\mathrm{MPa} / \mathrm{K})$ & 0.823 \\
$\mu(\mathrm{GPa})$ & 45 \\
$g_{0}$ & 1.600 \\
$\mathrm{~A} / \mathrm{B}$ & 0.250 \\
$\dot{\varepsilon}_{0}\left(\mathrm{~s}^{-1}\right)$ & $10^{-7}$ \\
$a_{0}(\mathrm{MPa})$ & 2100 \\
$a_{1}(\mathrm{MPa})$ & 7.610 \\
$a_{2}(\mathrm{MPa})$ & 0.044 \\
$\mathrm{~T}_{\mathrm{ref}}$ & $\mathrm{Room}$ temperature \\
$\mathrm{T}_{\mathrm{melt}}(\mathrm{K})$ & 1268 \\
$m$ & 0.900 \\
$\mathrm{D}_{0}$ & 0.000 \\
$\mathrm{D}_{\mathrm{cr}}$ & 0.850 \\
$\varepsilon_{\mathrm{cr}} / \varepsilon_{\mathrm{th}}^{\mathrm{qs}}$ & 2 \\
$b_{1}$ & 1.014 \\
$b_{2}$ & - \\
$b_{3}$ & 0.020 \\
$\mathrm{~K}$ & 8 \\
\hline
\end{tabular}

flow theory with the isotropic hardening law (6). The isotropic damage evolution of the material is described by the Eq. (7). The degradation of the material response due to damage is described by Eq. (13). The material constants for the copper alloy are listed in Table 2 .

Numerical simulations have been performed with the commercial FE code ABAQUS/Explicit. The sheet has been meshed with quadrangular plane strain elements with reduced integration, denoted CPE4R in ABAQUS (ABAQUS, 2005). The FE mesh of the sheet and the boundary conditions are presented in Fig. 4. A very dense mesh has been defined in the shearing band (i.e. the zone between the punch corner radius and the die corner radius) and a coarse mesh has been used for areas not subjected to high stress levels. The tools have been considered as analytic rigid surfaces. The contact between the sheet and the tools has been described by the Coulomb friction model with a friction coefficient of 0.02. The adaptative mesh controls have been activated in ABAQUS/Explicit to allow remeshing. In order to predict the material damage evolution, the damage model (7) coupled with the hardening law (6) was implemented in ABAQUS/Explicit FE code via the VUMAT user's subroutine. During the FE simulations, the fracture initiation and the fracture propagation path have been simulated with the element deletion method.

\subsection{Validation of FE model}

FE simulations have been carried out with various material models: Johnson and Cook (Johnson and Cook, 1983) model, Gurson (Gurson, 1977) model and the hardening and damage model proposed herein (Husson, 2004; Husson et al., in press). The Johnson and Cook (Johnson and Cook, 1983) and Gurson (Gurson, 1977) models are standard models in the commercial FE code ABAQUS/Explicit. The commercial copper alloy material parameters for Johnson and Cook

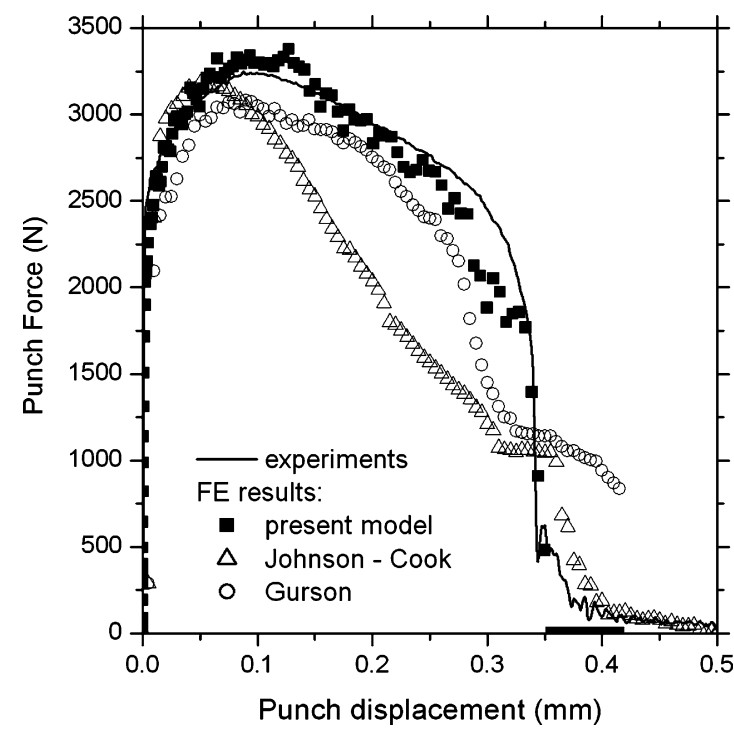

Fig. 5 - Experimental and numerical punch force vs. punch displacement curves obtained for a commercial copper alloy.

(Johnson and Cook, 1983) model and for the Gurson (Gurson, 1977) model have been taken from literature (Poizat et al., 2005). The experimental results have been taken from (Poizat and Ahzi, 2002). The FE results presented for Johnson and Cook (Johnson and Cook, 1983) model have been computed with a critical strain of $800 \%$ and the results for Gurson (Gurson, 1977) model have been computed with a critical void volume fraction of $18 \%$. The experimental curve and the different punch force-punch displacement curves predicted with ABAQUS/Explicit have been plotted in Fig. 5. The punch force-punch displacement curve obtained with the proposed model is in better agreement with the experimental curve than the two others predicted curves (i.e. the curves predicted with Johnson and Cook (Johnson and Cook, 1983) model and with Gurson (Gurson, 1977) model). The punch force-punch displacement curves tend to point out that the proposed model is more suitable model to simulate blanking processes.

Consequently, we have decided to compare the experimental sheared edge obtained by scanning electron microscopy analysis (Fig. 6a) with the predicted sheared edge using the proposed model (Fig. 6b). The following characteristic features of the sheared edge have been studied: rollover depth, burnish depth and fracture depth. The predicted burnish depth and the predicted fracture depth values are closer to the experimental values. The rollover depth is slightly overestimated by our simulations since the springback phenomena after unloading has not been considered. Nevertheless, the predicted sheared edge is clearly in agreement with the sheared edge obtained experimentally.

To conclude, the presented model predictions are in fair agreement with the experimental data. The coupled hardening and damage model proposed is suitable to simulate sheet metal blanking processes. It can be used to carry out a parametric study of blanking clearance, wear and friction effects on the characteristic features of sheared edge. 
(a)

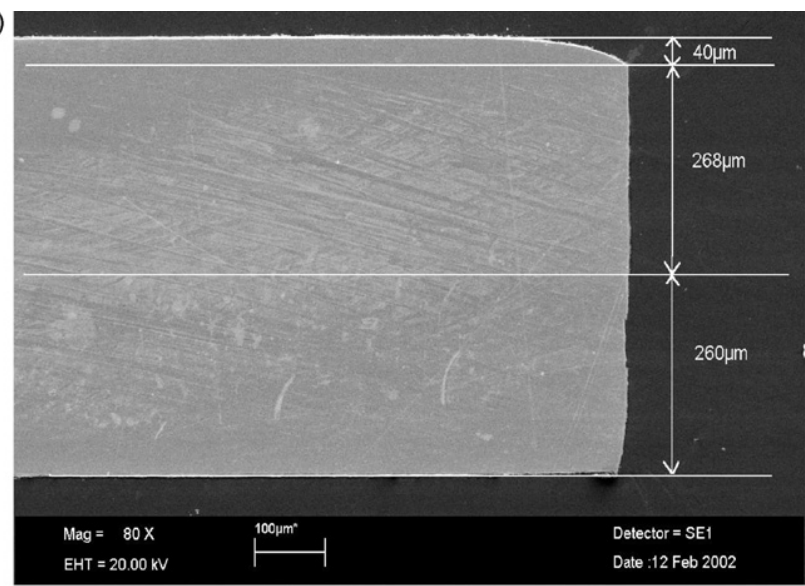

(b)

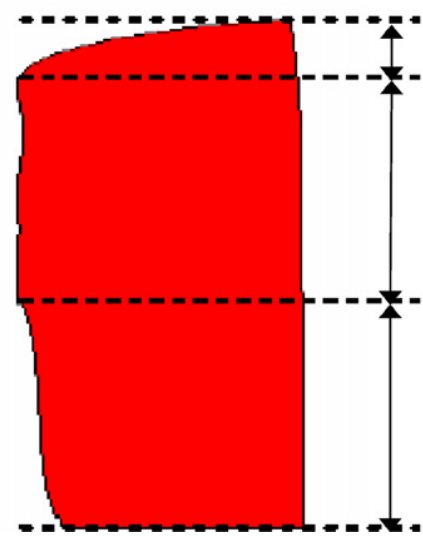

$75 \mu \mathrm{m}$

$260 \mu \mathrm{m}$

240um

Fig. 6 - Characteristic features of sheared edge achieved by scanning electron microscopy analysis (a) and of sheared edge predicted by FE simulations (b).

\section{Influence of blanking clearance, tool wear and friction on sheared edge quality}

In the following section, we present the effects of blanking clearance, tool wear and friction on the sheared edge quality. The relative rollover depth is referred to as $a / t_{0}$, the relative burnish depth as $s / t_{0}$, the relative fracture depth as $f / t_{0}$ and the relative burr height as $b / t_{0}$. Here $t_{0}$ is the initial thickness of the sheet.

\subsection{Blanking clearance}

The clearance between the punch and the die (i.e. the blanking clearance) is a major process parameter in blanking process. As it is well established in the literature, blanking clearance has a significant effect on blanking force and on sheared edge quality. In this study, various FE simulations have been performed for blanking clearance values ranged between $15 \mu \mathrm{m}$ and $110 \mu \mathrm{m}$.

The characteristic features of sheared edge have been plotted with respect to blanking clearance, Figs. 7 and 8 . It can be noted that the predicted burr height is null for all clearance values, Fig. 7, with the tooling geometry defined in Table 1. This result is in agreement with the experimental tendency

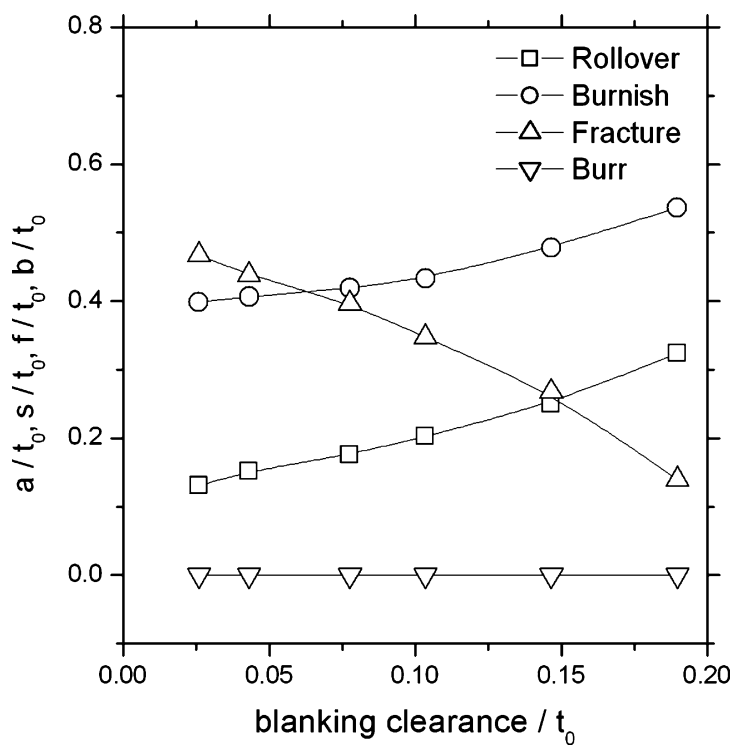

Fig. 7 - Effect of blanking clearance on the characteristic features of sheared edge predicted by FE simulations.

observed by other authors (Hatanaka et al., 2003a,b). However, blanking clearance has a strong effect on rollover and fracture depth. In the blanking process, the sheet metal is bent, then, with the increase of punch penetration, the shearing process occurs. The increase of blanking clearance allows the material to flow more easily between the punch and the die. As a result, the bent stage increases and, as expected, the predicted rollover depth increases. Therefore, crack initiation occurs for a higher punch penetration. Crack initiation is delayed and the predicted fracture depth decreases.

The fracture angle predicted by FE simulations is presented in Fig. 8. As the blanking clearance increases, the predicted fracture angle increases significantly. For small clearance values, the cracks simultaneously initiate under the punch corner

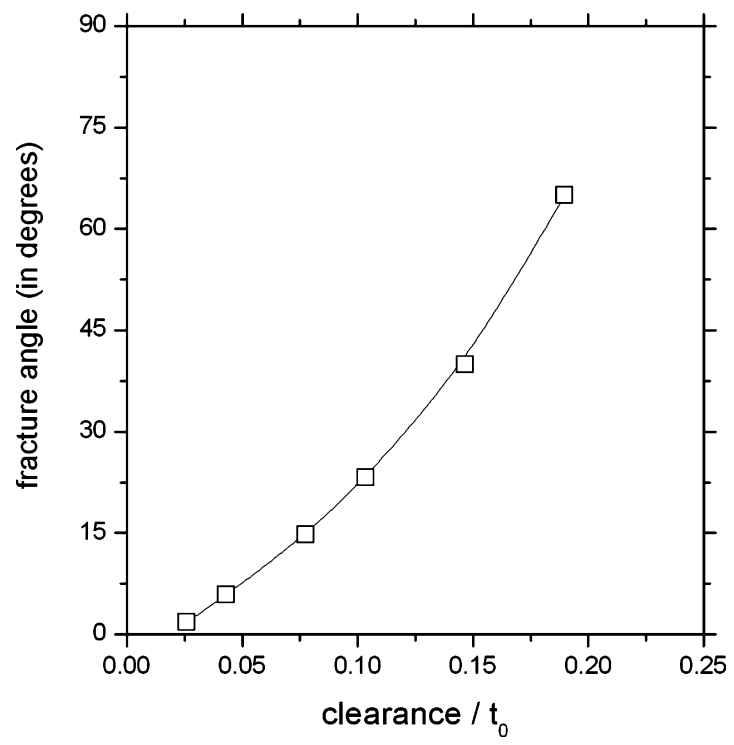

Fig. 8 - Fracture angle evolution predicted by FE simulations as a function of blanking clearance. 


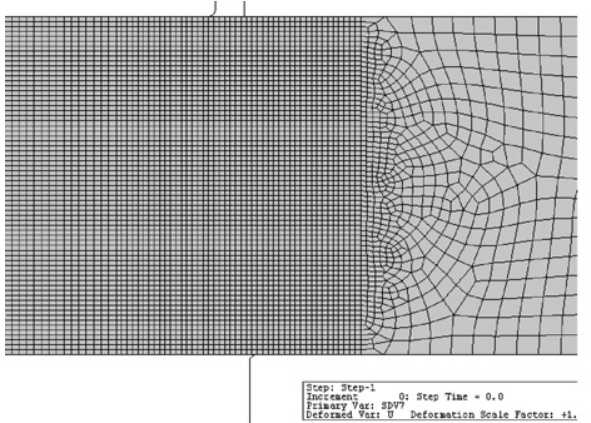

Punch displacement $/ t_{0}=0.00$

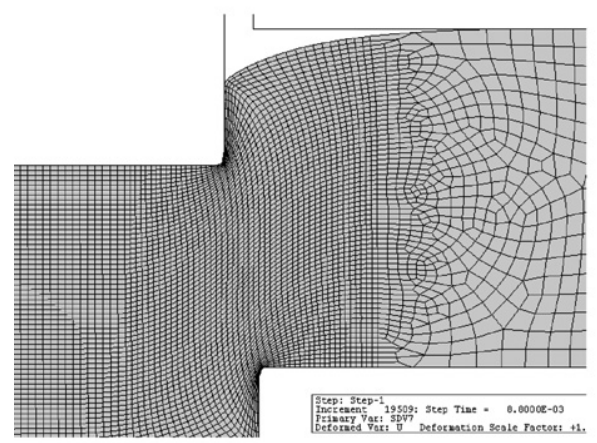

Punch displacement $/ t_{0}=0.40$

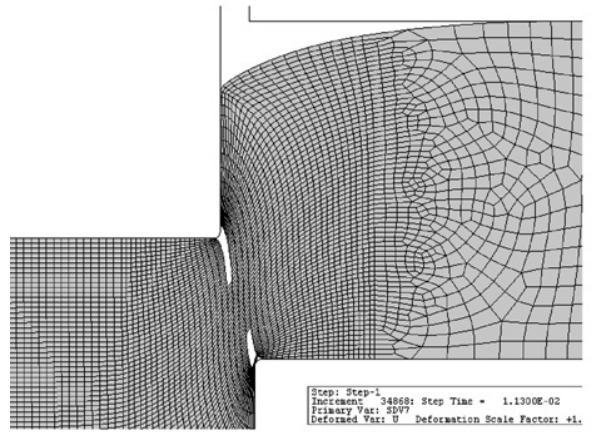

Punch displacement $/ t_{0}=0.64$

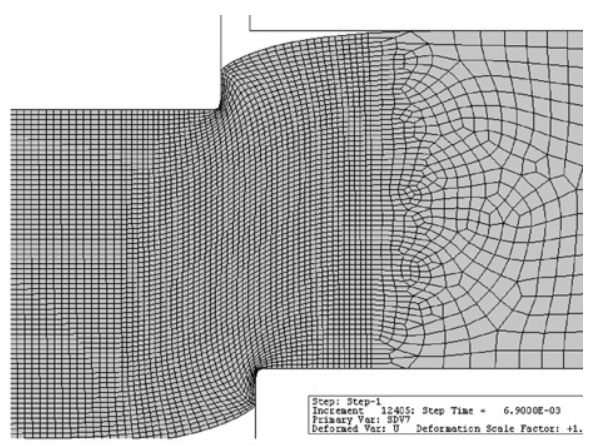

Punch displacement $/ t_{0}=0.24$

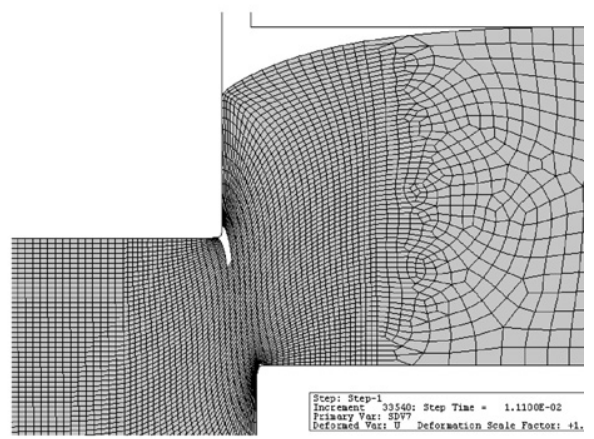

Punch displacement $/ t_{0}=0.62$

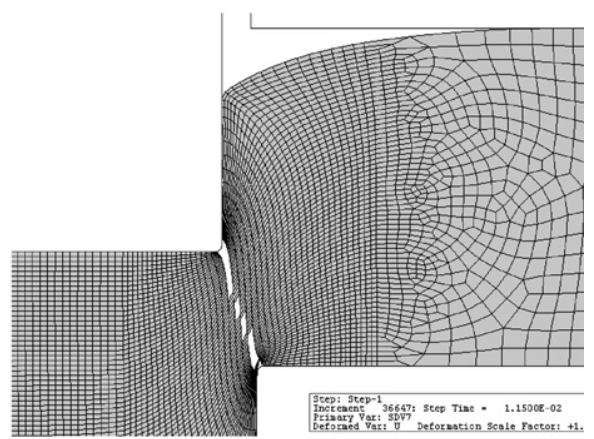

Punch displacement $/ t_{0}=0.66$

Fig. 9 - Example of simulated crack initiation and growth for a large blanking clearance value.

radius and over the die corner radius. Then the cracks propagate along a straight line connecting both primary cracks. On the contrary, for large clearance values, Fig. 9, a primary crack occurs under the punch corner radius, then propagates in the direction of die corner radius with a slope proportional to blanking clearance. With the increase of punch penetration in the sheet, a second crack occurs over the die corner radius. The delay of occurrence of this second crack increases with the increase of blanking clearance. Both continuously propagate and finally connect to each other leading to sheet separation. These results are in agreement with experimental and numerical results in the literature (Kalpakjian, 1997; Hatanaka et al., 2003a,b).

\subsection{Tool wear}

The friction between tools and sheet metal induces a slow degradation of the external surface of tools. The degradation is principally located on the corner radii of tools. This phe- nomenon is called wear. Tool wear influence can be accounted for in our FE simulations by changing the values of punch and die corner radii. Numerical investigations into blanking process have been carried out for different tool wear state (i.e. for different punch and die corner radii values which could also be called wear radii). Punch and die corner radii values are ranged between $0.01 \mathrm{~mm}$ and $0.10 \mathrm{~mm}$. A punch or die corner radii of $0.01 \mathrm{~mm}$ corresponds to tools with sharp edges. A corner radius value of $0.10 \mathrm{~mm}$ corresponds to punch and die with dull edges.

For a better understanding of tool wear effect on sheared edge different sheared edges, achieved by FE simulations, have been plotted in Fig. 10. As expected, whereas tools with dull edges and high blanking clearance deteriorate sheared edge quality, tools with sharp edges and weak blanking clearance enhance the sheared edge quality.

The predicted evolutions of sheared edge characteristics features have been plotted as a function of tools wear state, Figs. 11-15. Tools with dull edges (i.e. tools with high wear 


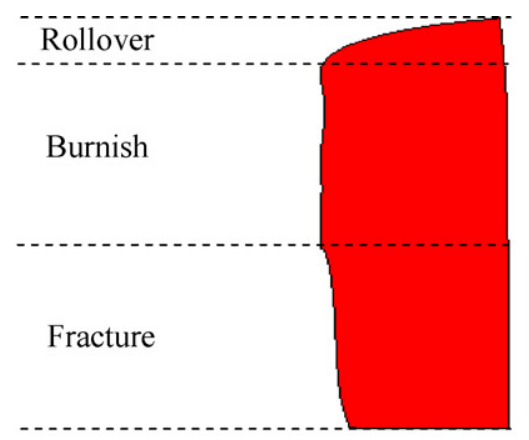

Blanking clearance of $15 \mu \mathrm{m}$

Punch and die corner radii of $10 \mu \mathrm{m}$

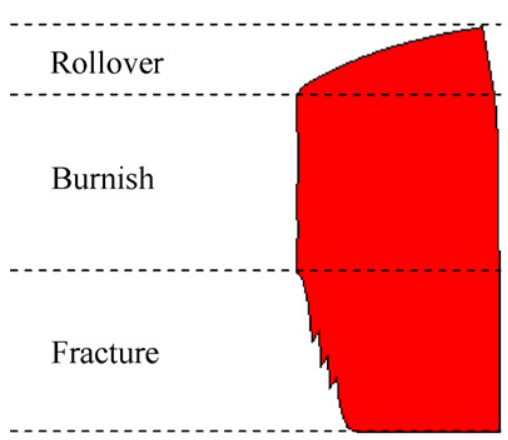

Blanking clearance of $60 \mu \mathrm{m}$

Punch and die corner radii of $10 \mu \mathrm{m}$

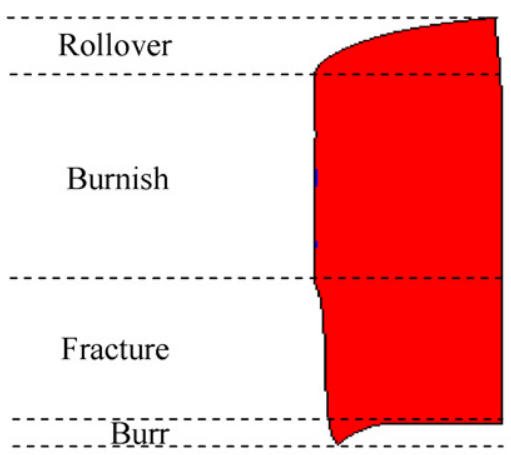

Blanking clearance of $15 \mu \mathrm{m}$

Punch and die corner radii of $75 \mu \mathrm{m}$

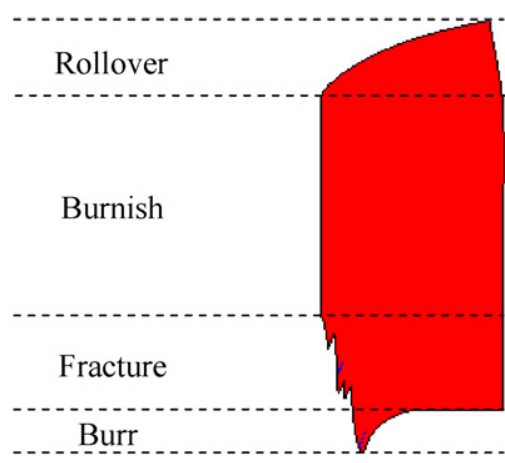

Blanking clearance of $60 \mu \mathrm{m}$

Punch and die corner radii of $75 \mu \mathrm{m}$

Fig. 10 - Sheared edges predicted by FE simulations for different wear states (i.e. punch and die corner radii) and different blanking clearances.

radii values) promote material flow instead of allowing shearing deformation. Tool wear therefore affects sheared edge, so does blanking clearance. However, blanking clearance effect on sheared edge quality seems to be more significant than tool wear effect. Blanking clearance increase promotes tool wear effect on sheared edge. As expected the burr height increases as blanking clearance and tool wear increase, Fig. 14. Moreover,

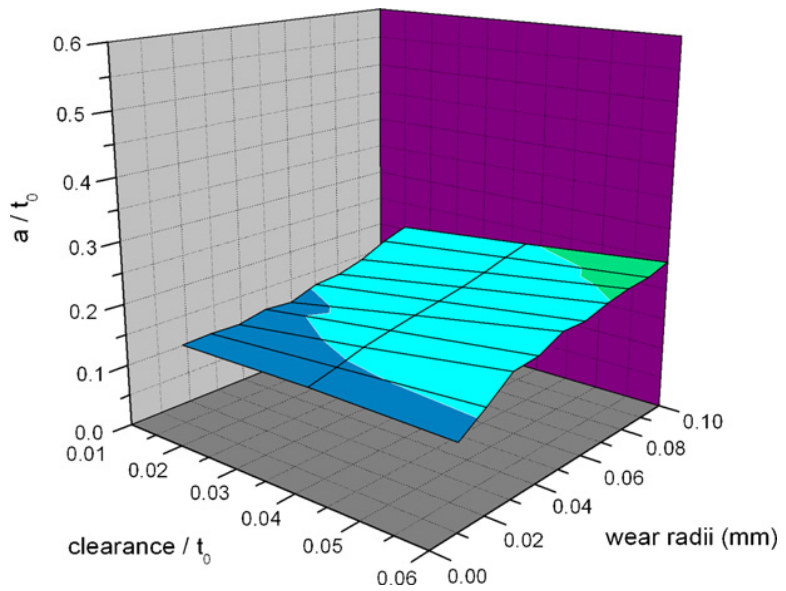

Fig. 11 - Effect of tool wear on rollover depth for a blanking clearance ranged between $15 \mu \mathrm{m}$ and $60 \mu \mathrm{m}$. from the FE predictions, tool wear appears as a major factor in burr formation (in agreement with (Kalpakjian, 1997)).

The fracture angle predicted by FE simulations has been presented in Fig. 15. Fracture angle increases when tool wear increases. But tool wear effect is more pronounced when the blanking clearance is important. Blanking clearance increase reinforces tool wear effect on fracture angle. The FE predictions of tool wear and blanking clearance effects are well

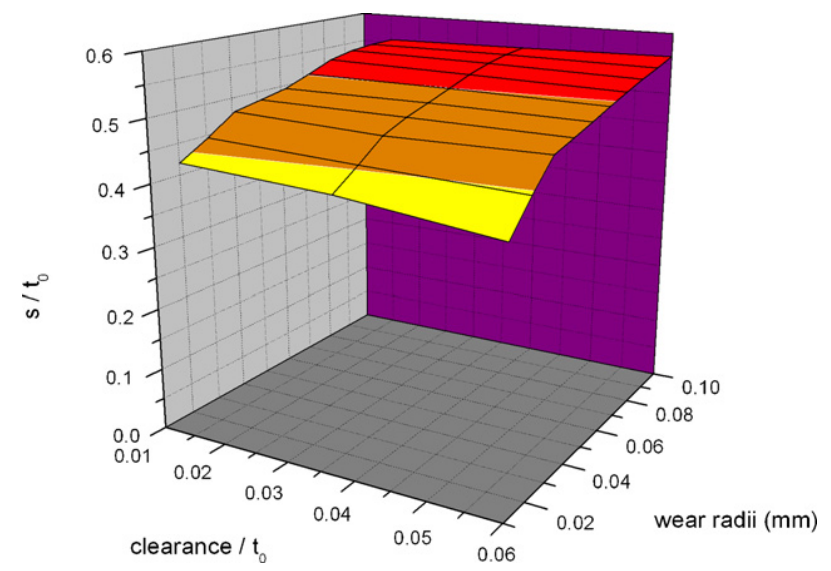

Fig. 12 - Effect of tool wear on burnish depth for a blanking clearance ranged between $15 \mu \mathrm{m}$ and $60 \mu \mathrm{m}$. 


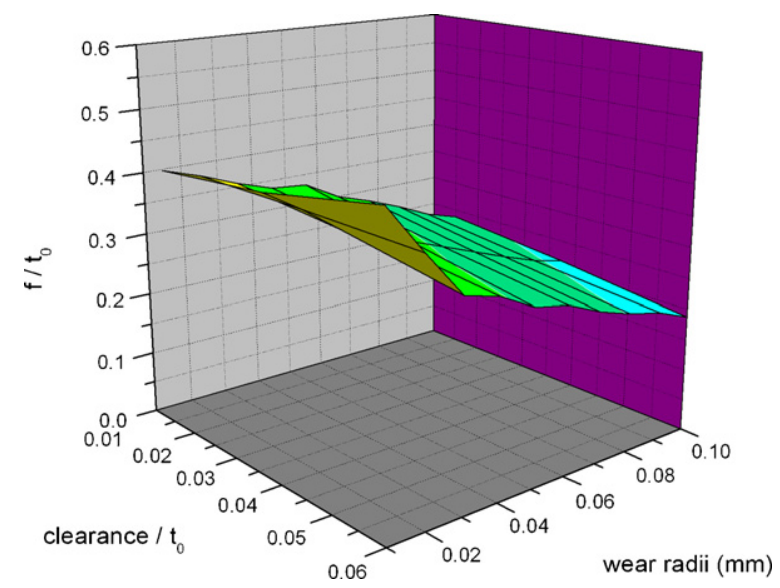

Fig. 13 - Effect of tool wear on fracture depth for a blanking clearance ranged between $15 \mu \mathrm{m}$ and $60 \mu \mathrm{m}$.

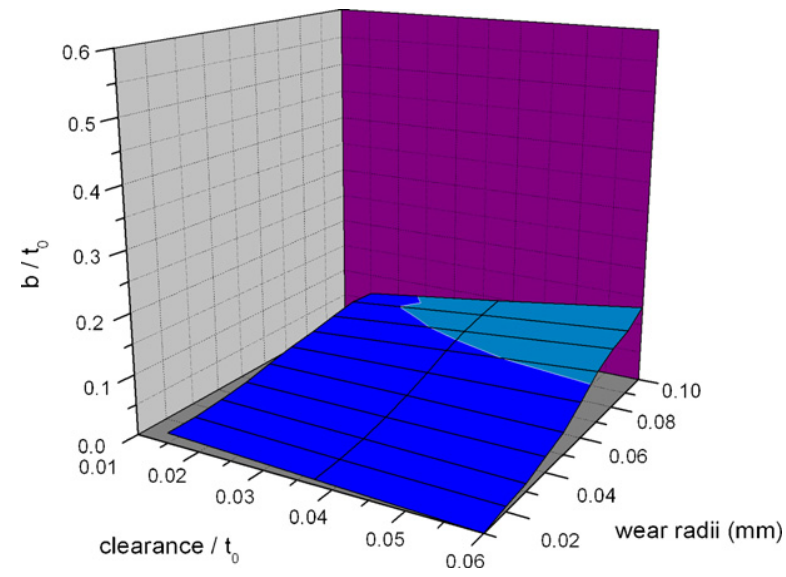

Fig. 14 - Effect of tool wear on burr height for a blanking clearance ranged between $15 \mu \mathrm{m}$ and $60 \mu \mathrm{m}$.

in agreement with the experimental tendencies observed by Hambli (Hambli, 2002).

\subsection{Friction}

In the following section, FE predictions are presented for punch and die corner radii equal to $30 \mu \mathrm{m}$, which corresponds

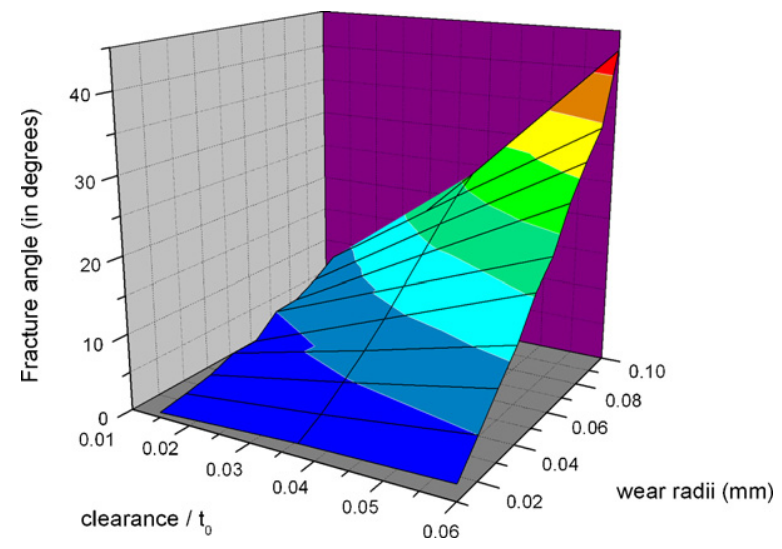

Fig. 15 - Effect of tool wear on fracture angle for a blanking clearance ranged between $15 \mu \mathrm{m}$ and $60 \mu \mathrm{m}$.

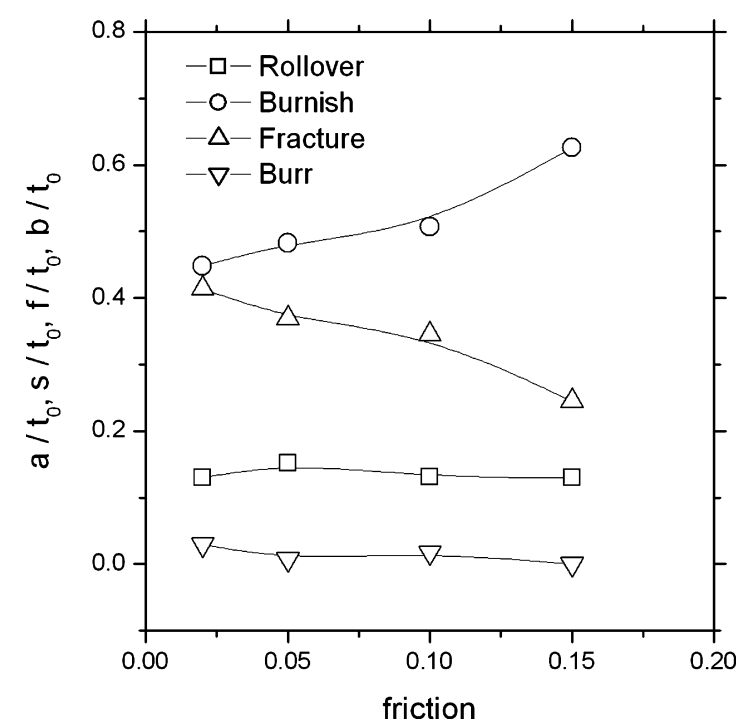

Fig. 16 - Friction effects on the characteristic features of sheared edge predicted by FE simulations.

to a moderate wear state. Friction coefficient varies from 0.02 to 0.15 . A friction coefficient value of 0.02 corresponds to medium lubrication while a value of 0.15 corresponds to a contact with poor lubrication.

The evolution of rollover depth, burnish depth, fracture depth and burr height (i.e. characteristic features of sheared edge), normalized with respect to thickness, have been plotted in Fig. 16. The burr height and the rollover depth remain nearly constant while the friction coefficient increases. The fracture angle evolution, which is not presented here, can be assumed constant since fracture angle varies from $1.2^{\circ}$ to $2.0^{\circ}$ when friction coefficient varies from 0.02 to 0.15 . The burnish depth however increases and the fracture depth decreases as friction increases. Friction effect on the burnish and fracture depth is comparable to blanking clearance effect or wear effect. To conclude, it can be assumed that, for copper alloys, friction has a negligible effect on sheared edge since only burnish and fracture depths are slightly affected.

\section{Conclusion}

A new viscoplastic hardening model coupled with a new damage model has been presented and applied to FE simulations of thin copper sheet blanking. We demonstrated that the viscoplastic hardening and damage models presented here are suitable to predict blanking force evolution and characteristic features evolution of sheared edge. The effects of blanking clearance, tool wear and friction on sheared edge have been studied. The FE simulations have pointed out that a high blanking clearance or a high tool wear or a high friction affects the quality of predicted sheared edges. It has to be noted however that tool wear effect is more pronounced when blanking clearance is higher. Friction effect on sheared edge is negligible since it only affects burnish and fracture depths. Therefore, blanking clearance and tool wear are the most significant blanking process parameters affecting sheared edge quality. 


\section{Acknowledgement}

This research was funded by FCI Connectors. The authors are grateful to Dr. M. Zindine, Director of the Corporate Research Center of FCI Connectors.

\section{REFERENCES}

ABAQUS/Explicit, 2005. Version 6.5 Manuals, Hibbitt, Karlsson and Sorensen Inc., Pawtucket, USA.

Brokken, D., Brekelmans, W.A.M., Baaijens, F.P.T., 1998. Numerical modelling of the metal blanking process. J. Mater. Process. Technol. 83, 192-199.

Cockroft, M.G., Latham, D.J., 1968. Ductility and workability of metals. J. Inst. Metals 96, 33-39.

Dufailly, J., 1980. Modélisation mécanique et identification de l'endommagement plastique des matériaux, $\mathrm{PhD}$ Thesis, Université Pierre et Marie Curie ParisVI, France.

Flinn, J.E., Field, D.P., Korth, G.E., Lillo, T.M., Macheret, J., 2001. The flow stress behavior of OFHC polycrystalline copper. Acta Mater. 49, 2065-2074.

Follansbee, P.S., Kocks, U.F., 1988. A constitutive description of the deformation of copper based on the use of the mechanical threshold stress as an internal state variable. Acta Metall. 36, 81-93.

Gurson, A.L., 1977. Continuum theory of ductile rupture by void nucleation and growth. Part I. Yield criteria and flow rules for porous ductile media. J. Eng. Mater. Technol. 99, 2-15.

Hambli, R., 2002. Design of experiment based analysis for sheet metal blanking processes optimisation. Int. J. Manufact. Technol. 19, 403-410.

Hambli, R., Potiron, A., 2000. Finite element modelling of sheet-metal blanking operations with experimental verification. J. Mater. Process. Technol. 102, 257-265.

Hatanaka, N., Yamaguchi, K., Takakura, N., 2003a. Finite element simulations of the shearing mechanism in the blanking of sheet metal. J. Mater. Process. Technol. 139, 64-70.

Hatanaka, N., Yamaguchi, K., Takakura, N., Iizuka, T., 2003b. Simulation of sheared edge formation blanking of sheet metals. J. Mater. Process. Technol. 140, 628-634.
Husson, C., 2004. Simulation numérique de la mise en forme des tôles métalliques appliquées à la connectique: étude de la découpe, PhD Thesis, Univeristé Louis Pasteur, Strasbourg, France.

Husson, C., Daridon, L., Ahzi, S., in press. A model for elastic? viscoplastic deformation and damage evaluation in materials under a wide range of strain rates and temperature.

Johnson, G.R., Cook, W.H., 1983. A constitutive model and data for metals subjected to large strains, high strain rates and high temperatures. In: Proceedings of the 7th International Symposium on Ballistics, The Hague, Netherlands, pp. 541-546.

Kalpakjian, S., 1997. Manufacturing Processes for Engineering Materials, 3rd ed. Addison Wesley, Menlo Park, USA.

Klingenberg, W., Singh, U.P., 2005. Comparison of two analytical models of blanking and proposal of a new model. Int. J. Mach. Tools Manufact. 45, 519-527.

Kovàcs, I., Vörös, G., 1996. On the mathematical description of the tensile stress-strain curves of polycrystalline face centered cubic metals. Int. J. Plast. 12, 35-43.

Lemaitre, J., 1985. A continuum damage mechanics model for ductile fracture. J. Eng. Mater. Technol. 107, 83-91.

Lemiale, V., 2004. Contribution à la modélisation et à la simulation numérique du découpage des métaux, $\mathrm{PhD}$ Thesis Univeristé de Franche-Comté, Besançon, France.

Maudlin, P.J., Davidson, R.F., Henninger, R.J., 1990 Implementation and assessment of the mechanical threshold stress model using the EPIC2 and PINON computer codes, Los Alamos National Laboratoty Report, Ref. LA-11895-MS.

McClintock, F.A., 1968. A criterion for ductile fracture by the growth of holes subjected to multi-axial stress states. J. Appl. Mech. 35, 363-371.

Poizat C., Ahzi S., 2002. Numerical simulation of cold metal forming: blanking, coining and bending (FCI, Confidential Report), Strasbourg, France.

Poizat, C., Campagne, L., Daridon, L., Ahzi, S., Husson, C., Merle, L., 2005. Modeling and simulation of thin sheet blanking using damage and rupture criteria. Int. J. Forming Processes 8, 29-47.

Tanner, A.B., McGinty, R.D., McDowell, D.L., 1999. Modeling temperature and strain rate history effects in OFHC Cu. Int. J. Plast. 15, 575-603.

Taupin, E., Breitling, J., Wu, W.-T., Altan, T., 1996. Material fracture and burr formation in blanking results of FEM simulations and comparison with experiments. J. Mater. Process. Technol. $59,68-78$. 